\title{
O VIÉS AMERICANO DO MÉTODO MONTESSORI EM SÃO PAULO: CIRIDIÃO BUARQUE E MARY BUARQUE
}

\author{
Simone Ballmann de Campos \\ Universidade Federal de Santa Catarina (UFSC), Florianópolis, Santa \\ Catarina, Brasil
}

\begin{abstract}
Resumo: Montessori constituiu, em 1907, em Roma, uma escola pública para crianças em situação de risco, a Casa dei Bambini, que difundida transnacionalmente configurou práticas e pensamento educacional inovadores. O objeto desta narrativa historiográfica foi estudar a institucionalização do Método Montessori no Brasil, problematizando a sua forma de apropriação e identificando por que o método é relacionado principalmente ao uso de materiais didáticos específicos e de mobiliário adequado ao tamanho das crianças. Foi constatado que a primeira escola montessoriana no Brasil atendeu ao público infantil, em São Paulo, no ano de 1915, num investimento particular de Ciridião Buarque e Mary Buarque. Essa pedagogia se irradiou por intermédio das apropriações realizadas pelos docentes da Escola Normal da Praça, e da legislação que indicava o uso de materiais didáticos de Montessori e de Froebel, mas de forma desarticulada de tais princípios pedagógicos. Evidências da utilização do Método Montessori em perspectiva não restrita ao uso de materiais didáticos foram encontradas nos programas infantis radiofônicos.
\end{abstract}

Palavras-Chave: História da Educação. Educação da Criança. Método Montessori. Instituições Educativas Brasileiras.

\section{PISTAS PARA COMPOR O ENREDO}

Após ser divulgado por adentrar os meandros educativos como proposta capaz de alfabetizar rapidamente, a matriz pedagógica montessoriana em circulação transnacional penetrou inicialmente no Brasil por um "viés americano", ensejado por Ciridião Buarque, a partir de 1915. Se a circulação do ideário montessoriano provinha de estudos e proposições de intelectuais independentes, com a implantação da "Escola Montessori Casa da Criança" pelo renomado professor Ciridião Buarque e por sua filha Mary, na capital de São Paulo, tal método recebeu ênfase no cenário educativo daquele Estado, pois os seus principais interlocutores durante as duas décadas subsequentes possuíam relação direta com a Escola da Praça, prestigiada instituição de ensino do país naquele período, e disseminadora das inovações pedagógicas para além das terras paulistanas. 
Neste escrito, buscando compreender a institucionalização do Método Montessori pelo cenário educativo, apresento uma trama relacional e política na qual a educação passa a ser o vértice do engajamento em prol do nacionalismo e do avanço do país, nas primeiras décadas da centúria passada. A identificação dos projetos brasileiros, desenvolvidos em tal período, apontam para permanências e contribuições do Método Montessori à educação brasileira, assim como ajudam a problematizar a apropriação parcial do mesmo.

Um indício encontrado no livro de Tisuko Morchida (1988), elaborado com base em sua tese a respeito das pré-escolas paulistas, direcionou-me a uma vasta pesquisa na Hemeroteca Nacional, local onde estão armazenadas as imagens dos jornais brasileiros, alguns com mais de um século. Nela encontrei material extenso e relevante que certamente pode auxiliar na construção da História da Educação em nosso país. Organizei o trabalho de maneira a analisar de forma crítica o que os impressos sobre o assunto abordavam, compará-los com a bibliografia existente, já inventariada, e com as fontes encontradas nos jornais da época e, ainda, concomitantemente, com os escritos de Montessori, num exercício de cotejamento.

Nessa esteira, de acordo com Gatti Jr. (2008), a pesquisa historiográfica efetiva-se por meio de materiais diversos, como bibliografia variada, impressos, manuscritos, fontes orais ou iconográficas. Cita o mesmo autor $(2008$, p.9) que "[...] o empreendimento da pesquisa sobre o ensino de História da Educação tem um amplo espectro ainda a realizar". Neste sentido, os suportes utilizados ampliam o cabedal geralmente utilizado na História da Educação por associarem as facilidades apresentadas pelos arquivos digitais à pesquisa, que pode ser realizada em qualquer local que tenha acesso à internet. Com isso, a costumeira prevalência da fonte escrita pode desabrochar, de forma interdisciplinar, para outras áreas marcadas pela história cultural, procurando superar limitações metodológicas resultantes de uma análise estrutural estreita e permitir "articular, de forma substantiva, e integrar, de forma intelectiva, os processos de institucionalização e de inovação educacional" (MAGALHÃES, 2004, p.92).

Nessa tessitura mesclada por informações alusivas ao Brasil e às outras nações veiculadas pela mídia impressa, os fios que compunham a trama provinham de áreas associadas e interferentes na educação, como a política, a economia, a medicina, a psicologia ou, ainda, a geografia. Nesse entremeio, as fontes utilizadas possibilitaram descortinar a presença de outros personagens, reconhecidos ou não no cenário historiográfico, e o acesso a algumas informações e relações com o contexto educacional vivenciado entre o princípio e meados do século passado, com as quais a perspectiva montessoriana interagiu e se alicerçou. Esses dados coletados contribuíram para a construção de novos vieses historiográficos que ajudaram a compor contextos e a (re)desenhar os caminhos traçados na apropriação e utilização das propostas educativopedagógicas citadas, trazendo ao palco alguns dos interessados pelas inovações que tais pressupostos suscitaram à educação brasileira. Nesse ínterim, ocupam este cenário Ciridião e Mary Buarque, principalmente.

Dessa forma, procurei encontrar "a superação da abordagem descritiva mediante uma historiografia problematizante, interpretativa, conceitual" (MAGALHÃES, 2004, 
p.136), em um estudo de História da Educação, cujo método de análise crítica, interpreta, contextualiza e coteja documentos e fontes abordados.

Assim, a estrutura textual é apresentada sob a modalidade de uma narrativa historiográfica, que corresponda "à construção de um sentido e de uma identidade, periodizando e mapeando as coordenadas histórico-geográficas de tempo e espaço, compreendendo e interpretando os contextos" (MAGALHÃES, 2004, p.160). E, também, biografando e dispondo os sujeitos conforme suas ações e as circunstâncias.

\section{A PRIMEIRA INSTITUIÇÃO MONTESSORIANA DO BRASIL: A CASA DA INFÂNCIA}

Antes de 1915, o professor Manoel Ciridião Buarque, que lecionava Pedagogia desde 1890 no atual Instituto Estadual Caetano de Campos (IECC) ou Escola da Praça, viajou aos Estados Unidos para conhecer e intervir em novos horizontes educacionais. De acordo com Bartolomeu Buarque de Holanda, em seu livro "Buarque: uma família brasileira: ensaio histórico-genealógico" (2007, p.159), Caetano de Campos convidou Ciridião Buarque a ministrar aulas e encontrou nele "o seu braço direito na agitada fase de remodelação da Escola Normal". Além de professor conceituado, Ciridião Buarque destacou-se em outras atuações educacionais. Nascido em Alagoas, havia estudado Direito na faculdade de Recife e, ao deslocar-se ao Rio de Janeiro, tornou-se professor de português do Colégio Pedro II por meio de concurso. Como jornalista, publicou artigos sobre educação, literatura e outros assuntos em jornais de São Paulo e no Distrito Federal (RJ), como também, fundou, em 1902, a Revista Educação", onde "promovia reuniões literomusicais para a apresentação de educadores, intelectuais e artistas brasileiros e estrangeiros" (HOLANDA, 2007, p.158). Além disso, fora diretor do Colégio Neutralidade, que junto com a Escola Americana haviam servido como modelo para a reforma da Escola Pública Normal, conforme o Decreto de 12 de março de 1890. Na seção "Em torno do ensino", sob o título "Nossos primeiros passos", sem revelar o autor, o Jornal Correio Paulistano, de 31/03/1935, evidencia que:

\footnotetext{
A primeira e mais notável reforma de nosso ensino público inspirou-se, como é sabido, na organização escolar, victoriosa de muitos títulos, inspirada na Escola Americana e da Escola Neutralidade, sendo a primeira dirigida por Horácio Lane e a segunda, primeiro por João Kopke e depois por Ciridião Buarque. E, por isso a primeira reforma da escola pública teve estrondoso êxito, conquistando logo todos os paulistas, porque todos os lares, sem distinção de cor, de religião e de política, mandaram seus filhos para os bancos da primeira Escola Modelo [...] Em resumo, podemos dizer que esses dois notáveis estabelecimentos, a Escola Americana e a Escola Neutralidade, tiveram grande influência na organização de nossas escolas, e que conseguiram implantar com êxito, entre nós:

-os melhores methodos americanos de ensino;

-os trabalhos manuaes;

-o ensino de musica;

-o ensino de gymnastica;

-as promoções pelos trabalhos dos alumnos no correr do anno, e não no exame final; -a organização de um typo escolar para os centros urbanos e outro para a zona rural, com material didactico apropriado (JORNAL CORREIO PAULISTANO, 1935, p. 20).
} 
A influência de Ciridião Buarque no ensino paulista ocorreu tanto na relação com a tendência americana de ensino, como na proposição de um currículo baseado na mesma, que, por sua vez, abarcava a educação física, trabalhos manuais e uma avaliação processual durante o ano letivo, ou seja, considerando o desenvolvimento do aluno. Assim, após representar o estado de São Paulo no Segundo Congresso de Instrução Primária e Secundária, em 1912, "[...] foi-lhe confiado à sua direção uma viagem de estudos com um grupo de jovens aos Estados Unidos, cujo sistema de educação sempre foi admirador" (IECC, 2015). Em Nova York, encaminhou brasileiros às escolas norteamericanas, incentivou as relações culturais entre o Brasil e os Estados Unidos e, a convite do diretor da Universidade de Colúmbia ${ }^{2}$, fundou o primeiro curso de português naquela nação, com o intuito de difundir "o ensino de nossa língua entre os americanos que julgavam suficiente para as suas relações com o nosso país os estudos e conhecimentos do espanhol". Assim, originalmente Ciridião criou tanto o primeiro sistema de intercâmbio entre alunos como o de difusão de nossa língua materna no exterior: "Fez tudo isso sem a ajuda governamental, numa época em que todas as atenções culturais voltavam-se para a Europa" (IECC, 2015). Pelo uso, num modo de fazer peculiar e inédito, racionalizou a pedagogia escolar instituindo outras alternativas educacionais.

Voltando ao Brasil, em 1915, reassumiu seu cargo de Psicologia e Pedagogia na Escola Normal. Também instituiu e administrou, com sua filha Maria América Marcondes Buarque, conhecida como Mary Buarque, a primeira escola montessoriana no país (Fig. 1). Ciridião havia se empenhado para que o ensino público brasileiro se consolidasse e para que a cultura nativa fosse reconhecida internacionalmente. Nesta perspectiva, Nagle (1974, p.100), realçou que no princípio do século passado era latente o sonho republicano de "pela instrução, formar cívica e moralmente, de maneira a colaborar para que o Brasil se transformasse em uma Nação à altura das mais progressivas civilizações do século".

Figura 1- Escola Montessori

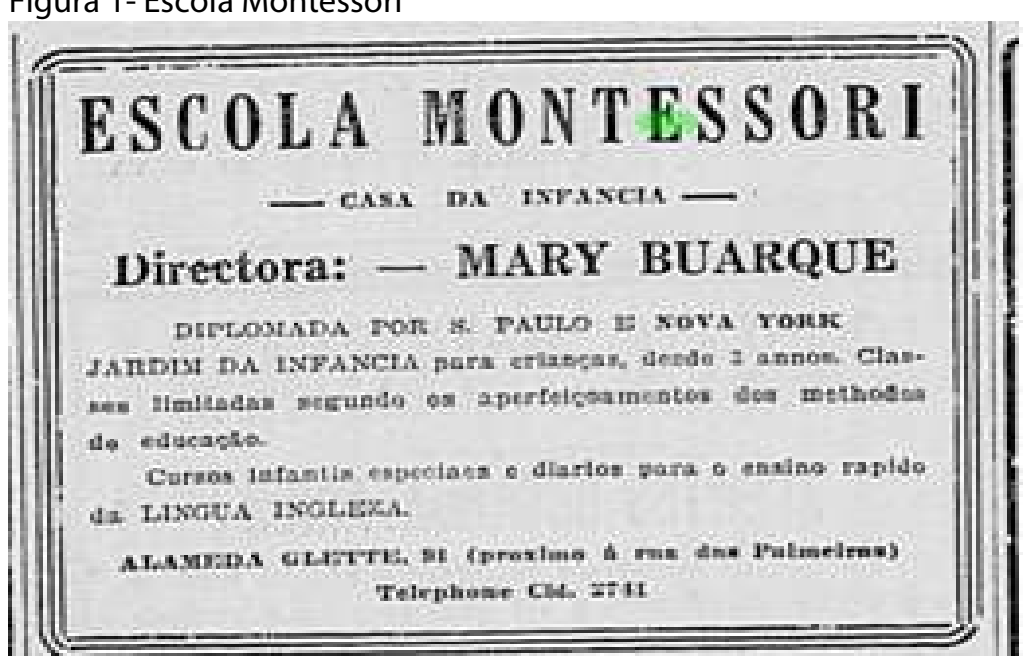

Fonte: Correio Paulistano, 31 de março de 1927. 
CAMPOS, S. B.

Nesse contexto, a primeira instituição montessoriana brasileira foi denominada de Casa da Infância e se localizava primeiramente à Avenida Angélica, n²4, na capital paulista (KISHIMOTO, 1988). Em 1927 (CORREIO PAULISTANO, 1927b), por sua vez, a escola encontrava-se situada à Alameda Glete, no 91, na mesma capital (endereço onde atualmente foi edificado um prédio) e era dirigida pela família Buarque.

Maria América Marcondes Buarque nasceu em 03.10.1896 e faleceu em 18.12.1970, São Paulo, SP. Professora, educadora, compositora e escritora. Fundou e dirigiu com seu pai a Escola Montessori, Casa da Infância, moldada nos modernos métodos de ensino observados por ambos nos Estados Unidos, onde Mary especializou-se no Colégio de Professores, da Universidade de Colúmbia, em Nova York. Mary Buarque precocemente demonstrava seu talento para as artes, a música e a poesia e, sobretudo, dava continuidade ao projeto educacional inicialmente idealizado por seus pais. Dedicou-se mais de meio século ao ensino infantil [...] Criou festivais de música e foi a primeira mulher a fazer um programa infantil de rádio, o Pequenópolis. (HOLANDA, 2007, p.354).

O anúncio postado no jornal Correio Paulistano com o intuito de divulgar a Escola Montessori: Casa da Infância, notabiliza a formação da professora responsável pela Instituição de Ensino, Mary Buarque, que, diplomada em Nova lorque trouxe para o Brasil uma perspectiva educacional valorizada no meio educativo americano da época.

Maria Montessori havia desembarcado pela primeira vez nos Estados Unidos em 1913, no auge de sua fama, quando jornais como o New York Times dedicaram páginas inteiras a entrevistas com "uma das mulheres mais interessantes da Europa", cujo método de ensino revolucionava o sistema educacional do mundo (KRAMER, 1988). Com um nome correlato à Casa dei Bambini italiana, o estabelecimento de ensino paulista inaugurado por Mary e seu pai também foi destinado a um público com idade a partir dos três anos, assim como nas escolas italianas fundadas pela doutora. Ademais, a Escola Montessori: Casa da Infância também seria local para o ensino da língua inglesa, o que denota que a família Buarque utilizou astuciosamente, da mesma forma que fizera nos Estados Unidos, o ensino de uma língua diferente da nacional como possibilidade de auferir fundos e de fazer circular uma inovação necessária ao cenário político e econômico do país.

\section{UM DOS VIÉSES NA DIFUSÃO DO MÉTODO MONTESSORI NO BRASIL: O ESTADUNIDENSE}

Outras reportagens e notas em jornais, sobretudo entre 1917 e $1936^{3}$, noticiaram eventos educativos, culturais, musicais ou beneficentes, nos quais se destaca a presença de Mary Buarque. Em alguns deles, participou com Lúcia Pacheco Jordão, como no "Terceiro Congresso Panamericano da Criança", ocorrido no Rio de Janeiro, de 29 de agosto a 2 de setembro de 1922, no qual a conferência de abertura, proferida por Pedro Deodato de Moraes ${ }^{4}$, teve como tema "A educação da Infância pelo Método Montessori" ${ }^{5}$.

Na ocasião, Mary Buarque e Lúcia Pacheco Jordão apresentaram um relato sobre as "Observações práticas em suas escolas tipo Montessori" (CORREIO PAULISTANO, 1922a e 1922b). As escolas montessorianas agregaram uma nova perspectiva na dimensão pedagógica do ensino brasileiro. Mary Buarque e Lúcia Pacheco cativaram o público do Terceiro Congresso Americano da Criança ao montarem uma sala de demonstração da 
utilização do Método Montessori (KISHIMOTO, 1988), que tinha como pressuposto a autoeducação do aluno. Em outros artigos do mesmo período (JORDÃO, 1923), Lúcia concedeu ênfase à formação moral que o referido Método possibilitava ao educando, numa ótica similar à utilizada por Piaget posteriormente.

As escolas "typo Montessori", como referencia a reportagem citada, apresentavam uma forma distinta de ensino, então se difundindo em nosso país. Se a palavra "tipo" foi concebida como um instrumento de análise para permitir a comparação entre a realidade e o mesmo, esta Instituição de Ensino serviria como um modelo acentuado do que era característico ou fundante no estudo montessoriano, abordando as condições ideais para as quais o professor deveria atentar em relação à sua atuação no ambiente escolar e com a criança.

A apresentação realizada no Terceiro Congresso Americano da Criança propiciou o entendimento de que o Método Montessori e o princípio da autoeducação haviam sido adotados por outros estabelecimentos de ensino, conforme esclarece Kishimoto (1988, p.154):

Embora as primeiras instituições particulares de educação infantil tenham optado pela linha froebeliana, a partir de 1915, a Escola Montessori, [...] tendo em sua direção Mary Buarque, diplomada pela Escola Normal da Praça e pela Universidade de Colúmbia, inicia um trabalho com crianças desde 3 anos de idade, utilizando a metodologia montessoriana. Essa mesma orientação teórica é opção do jardim de infância do Externato Pacheco Jordão, situado à rua Consolação, n 38, em São Paulo, de propriedade de Lúcia e Helena Pacheco Jordão. O envolvimento de Lúcia na metodologia montessoriana transparece na publicação do artigo "O desenvolvimento moral da criança no jardim de infância' (Jordão, 1923, p. 39), no qual defende o princípio montessoriano de autoeducação, como forma de libertar a criança da pressão dos adultos e transformá-la em um ser capaz de pensar, sentir e agir por conta própria. $O$ interesse por essa tendência metodológica leva-a a participar do $3^{\circ}$ Congresso Americano da Criança, realizado no Rio de Janeiro, em setembro de 1922, no qual defende o tema 'A influência da orientação Montessori na vida da criança' (JORDÃO, 1922 apud KISHIMOTO, 1988, p. 154).

Já no que se refere à escola implantada pela família Buarque para atender a um público seleto da capital paulista, por meio dos anúncios realizados no Jornal Correio Paulistano durante o ano de 1927, é possível afirmar que a atuação da Escola Montessori: Casa da Infância perpetuou-se até o início da década de 1930 sob a direção de Mary, mesmo com o falecimento de seu pai Manuel Ciridião Buarque em 1921. Contudo, posteriormente a essa data não foram encontradas nos jornais paulistanos menções à escola situada nos Campos Elíseos, o primeiro bairro nobre da cidade de São Paulo, onde se fixaram os fazendeiros de café, abalados pela crise de 1929. Tal crise também pode ter interferido na continuidade da escola.

Por outro lado, na reportagem apresentada pelo Correio Paulistano, em 6 de outubro de 1936, a respeito da implantação de um novo projeto cultural destinado à infância, "A Tarde da Criança", pertencente ao departamento infantil da Associação de Professores, anunciou-se que, em parceria com Corina de Sylos, integrante do grupo 
docente do Instituto de Educação da Universidade de São Paulo, trabalharia a "eficientíssima" professora Mary Buarque, fundadora e ex-diretora da Escola Montessori, diplomada em São Paulo e Nova York, e encarregada da Pequenópolis, a Hora Infantil da Rádio Kosmos ${ }^{6}$.

Em tal projeto, destinado aos sócios da Associação de Professores e à comunidade, ficaram evidentes alguns pressupostos montessorianos que compuseram a formação e a prática montessoriana de Mary Buarque, como a autoeducação, a liberdade de movimento da criança e a intervenção do adulto no aprendizado apenas se necessário, pois conforme o noticiário citado (CORREIO PAULISTANO, 1936),

[...] procurando seguir uma orientação pedagógica consciente, qual seja a da autoeducação, as crianças matriculadas nesse Departamento Infantil terão completa liberdade de movimento, dirigindo elas próprias os seus números, tendo a orientálas, de longe, apenas, a diretora e sua auxiliar.

Assim, mesmo não atuando diretamente numa escola montessoriana, Mary Buarque conservou a relação de aprendizagem característica da mesma, desenvolvendo "em suas pequenas frequentadoras as aptidões artísticas, cultivando-Ihes a sociabilidade e, ao mesmo tempo, afastando-as dos inevitáveis inconvenientes dos espetáculos infantis, cujos programas não são, geralmente, organizados especialmente para a infância" (CORREIO PAULISTANO, 1936). Desta maneira, a representação de criança, de infância e de ambiente adequado para a mesma, apropriada por Mary em seu trabalho com o Método Montessori e em suas vivências como professora foi ressignificada e, com a astúcia e a sutileza de um experiente mestre observador, deu origem a uma nova configuração do lugar da criança na mídia, promovendo para essa um atendimento e entendimento mais humano às suas necessidades e características infantis, enquanto destacava o potencial artístico das mesmas.

Como violonista, pianista, compositora, responsável por inúmeros recitais e saraus, Mary produziu um caminho que a diferenciou das mulheres do período em que viveu. Ao elaborar um programa de rádio específico para o público infantil, como montessoriana convicta, permitiu que a arte infantil conquistasse um novo olhar e um inaudito espaço social. Com isso, fez da sua apropriação um vetor que tornou possível a expansão do ethos montessoriano sob outras materialidades.

\section{A CONFIGURAÇÃO LEGAL DE UMA NOVA MATERIALIDADE ESCOLAR}

Além da arte, o curso oferecido por Mary na Associação de Professores também tinha como objetivo o refinamento social das crianças, com acesso à cultura, aulas de etiqueta e com ações beneficentes. Mesmo que oficialmente aberto à comunidade, os frequentadores do Projeto "Tarde da Criança" seguiriam as regras sociais preconizadas à elite de São Paulo:

No intuito de melhor preparar as crianças paulistas para a sociedade, serão ministradas, durante as Horas de Arte, conselhos e ensinamentos práticos das regras sociais. Para incentivar o amor à Pátria, à Natureza e às tradições [...]. A Tarde da Criança propõe-se a levar, regularmente, conforto moral e espiritual às crianças 
internadas em associações caridosas da capital, visitando-as e oferecendo-lhes momentos de agradável convívio (CORREIO PAULISTANO, 1936).

A primeira escola montessoriana no Brasil nasceu, assim, para o público infantil de um segmento social específico, num investimento particular que, por conseguinte, corroborava com o espírito inovador, nacionalista e de progresso encetado por uma elite que, na ausência de diretrizes educacionais governamentais afinadas, buscava consolidar seus ideais.

Em tal conjectura, entre o público e o privado, havia uma linha tênue que não demarcava os limites atribuídos a cada instância. Neste afã, a educação montessoriana no Brasil acompanhou a institucionalização da legislação educacional, do espaço escolar e da infância enquanto lugar social de necessidades específicas. No estado de São Paulo, especificamente, as discussões realizadas pelos intelectuais em torno de tais conceitos apresentaram um plexo único, principalmente no que se refere à organização para os infantes, pois se estabeleceu uma "querela" (KISHIMOTO, 1988) em torno da constituição de jardins de infância, visto que nem a escola primária havia se disseminado como necessária para alfabetizar toda a população.

Outra questão relativa ao referido nível de ensino em São Paulo ocorreu em função de o jardim de infância anexo à Escola Normal ter sido utilizado pela elite econômica e cultural da cidade. Desta maneira, a designação "jardim de infância" associou-se ao nome das instituições das crianças com maior poderio econômico, enquanto as que possuíam caráter assistencial eram chamadas de creches ou escolas maternais. Todavia, na comparação das proposições legais para escolas maternais e jardins de infância, no período de 1921 a 1925, não são percebidas diferenças significativas em termos de objetivos pedagógicos (KISHIMOTO, 1988). Contudo, foi possível identificar como a educação montessoriana adentrou a legalização do modus operandinos espaços infantis que se instauravam, institucionalizando a configuração de uma materialidade escolar e uma apropriação singular, tanto do que havia sido idealizado por Montessori quanto por Fröebel. Assim, tanto as Escolas Maternais quanto os Jardins de Infância aprovados pela legislação paulista dos anos 1920,

[...] pretendem iniciar a educação física, intelectual e moral servindo como intermediárias entre a escola e a família, conforme princípios de Froebel e Montessori:

Objetivos da Escola Maternal:

As escolas maternais são destinadas a iniciar a educação physica, intelectual e moral dos filhos de operários, servindo-se de intermediários entre a família e a escola. (decr. 3.708 , de 30 de abril de 1924, cap. II, art. 5०)

O ensino será ministrado pela educação dos sentidos, segundo as formas de Froebel e Montessori, adaptadas às condições do nosso meio. (decr. 3.708, de 30 de abril de 1924, cap. II, art. 6)

Objetivos do Jardim de Infância:

Os jardins de infância, destinados a ser intermediários entre a família e a escola, iniciam a educação física, intelectual e moral das crianças. (decr. 3.356, de 3 de maio de 1921, Título VII, cap I, art.72)

São atribuição da inspetora dos jardins de infância: 
[...] organizar com os professores o programa do jardim adotando as formas de Froebel às condições de nosso meio, submetendo-o à aprovação do diretor da escola normal. (decr. 3.356, de 3 de maio de 1921, art.82)

A orientação de seu ensino deverá obedecer, em parte, ao systema de Montessori, cujos aparelhos serão nelles usados. (decr. 3.858, de 11 de junho de 1925, arts. 57 e 58) (KISHIMOTO, 1988, p.39-40).

Ao declarar que as Escolas Maternais destinavam-se aos filhos de operários, o que havia se estabelecido culturalmente em torno da depreciação de tais instituições tornouse avalizado legalmente ${ }^{7}$. Já no que se refere ao cunho pedagógico, ambas as instituições utilizariam o embasamento froebeliano e montessoriano. Neste aspecto, o art.66, do Decr. 3847, de 14 de maio de 1925, também afirma que " $A$ ' directora, represente; organizar o programma e o horário da Escola, adoptando as formulas Froebel e Montessori às condições do nosso meio e submettendo-as à approvação da autoridade competente". Além disso, no capítulo III, artigo 16, ao referir-se às escolas maternais estabelece que "o material para a educação e desenvolvimento dos sentidos será o de Montessori accrescido de apparelhos que a pratica e a observação julgarem necessários". Ademais, no artigo 19, ao especificar os materiais que comporão cada sala de aula cita "a colleção do material Montessori com o respectivo armário" (SÃO PAULO, 1925). Também é a mesma legislação que discrimina que ao lado de cada Escola Maternal haverá uma creche para atender aos filhos dos operários, sendo a primeira frequentada por crianças de três a sete anos, e a segunda por aquelas que possuírem menos de três anos.

No que se refere à mobília das instituições, o decreto 3.708, de 30 de abril de 1924, também sustentava no art. 99: que a "[...] mobilia das escolas maternaes será a adoptada pelas escolas Montessori e jardins de infancia, adaptadas ao nosso meio" (SÃO PAULO, 1924).

A principal diferença entre os decretos citados é que em 1925 há a incorporação das creches para as crianças de 0 a 3 anos, que permanece amparada pela lei até a elaboração do Decreto n 5.884, de 21 de abril de 1933, que institui o Código de Educação do Estado de São Paulo e organiza em um único documento todos os níveis de ensino, até o secundário, mas não faz alusão à educação de 0 a 3 anos.

Em relação à Educação Infantil, destacamos no documento de 1933 que permanecem os sistemas de Froebel e Montessori como elementos a serem propagados e inspiradores de estudos e pesquisas sobre a educação:

Cap. I, Art 1 A educação publica no Estado de São Paulo compreende:

a) A educação pré-primaria ministrada nas escolas maternais em curso de dois anos a crianças de 2 a 4 anos e nos jardins da infância em curso de 3 anos, a crianças de 4 a 7 anos;

Art. 40 - Os jardins da infância e escolas maternais particulares ficarão sujeitas ao Serviço de Fiscalização e Orientação do Ensino Particular, com assistência do Serviço de Educação Infantil.

Cap. II, Art 38: Ao chefe do Serviço de Educação Infantil compete:

a) Animar o movimento pedologico com o intuito de vulgarizar os conhecimentos científicos sobre a criança;

b) Incentivar quando possível, a criação de escolas maternais e jardins da infância e particulares, anexos a estabelecimentos publicos ou colegios e fabricas; 
c) Providenciar sobre a criação de cursos de aperfeiçoamento no Instituto de Educação, com o fim de preparar um corpo de professores especializados na técnica da educação pré-primária;

d) propagar os sistemas de Froebel, de Montessori e outros, como ponto de partida para estudos e pesquizas que inspirem adaptadas de métodos e processos, de acordo com a características de nosso meio (SÃO PAULO, 1933, p.1;13).

Ainda na mesma legislação, no que se refere aos outros níveis de ensino, até o secundário, não há menção ao método ou a materiais montessorianos. Desta maneira, é possível evidenciar que legalmente, no Estado de São Paulo, o Método Montessori se ateve à Educação Infantil e que foi associado ao uso de materiais concomitante à indicação do método froebeliano. Provavelmente estas sejam as primeiras aferições ao uso do material montessoriano de forma desvinculada do método, não o considerando como um sistema de princípios mais amplo que o uso de materiais. Nesse viés transformador apresentado pela apropriação parcial tanto do Método Montessori como do froebeliano, ambos foram ressignificados, coisificando-se e, neste afã, receberam usos variados.

Por outro lado, se o Método de Froebel foi adotado no Brasil inicialmente nas Escolas Americanas, para que o sistema de ensino fosse consonante com o país e religião de origem do método citado, que somente mais tarde se expandiu para outras escolas públicas (KISHIMOTO, 1988), como teria o Método Montessori tornado-se parte integrante da legislação paulista? Ciridião Buarque, ou Sampaio Dória, também estudioso de Montessori (CORREIO PAULISTANO, 1920) e diretor de instrução pública, haveriam influenciado para que isso ocorresse? Ou, teria sido Zenaide Villalva de Araújo? Fica a indagação. De qualquer forma, conforme documento apresentado por Araújo (1923 apud KISHIMOTO, 1988, p.154),

Outra escola que aplica de modo consistente, desde 1927, a metodologia montessoriana é o jardim de infância anexo ao Colégio Villalva, cujas diretoras são Zenaide de Villalva de Araújo, membro da sociedade de Educação, e sua tia, Laura Villalva. A orientação metodológica da escola é definida por Zenaide que, desde 1923, atua como $2^{\circ}$ secretária da Sociedade de Educação e discute com Almeida Jr. e Lourenço Filho os problemas da educação do país. Em uma das reuniões, ela mostra a importância das adaptações de Froebel e Montessori para os jardins de infância e propõe a organização de uma comissão para o estudo do assunto. Recebe total apoio de Sampaio Dória que imediatamente sugere a inclusão das casas maternas nesse estudo. Dessa forma, Zenaide recebe incumbência de estudar a organização dos jardins de infância, escolas maternais e estabelecimentos similares, bem como a adaptação dessas entidades ao nosso meio. Como resultado do estudo, Zenaide constata a presença marcante dos princípios de Froebel e sugere como trabalho de inovação a complementação das atividades de educação infantil com a utilização de materiais montessorianos, tendo em vista o desenvolvimento da visão, tato, audição e o aprendizado da escrita e dos números (Araujo, 1923, p. 102-105). Provavelmente, o resultado do estudo deve ter interferido em sua decisão de renovar o jardim de infância sob sua orientação, desde 1922, com a introdução da metodologia montessoriana associada à froebeliana. 
O estudo realizado por Zenaide Villalva de Araújo interferiu na organização de sua escola privada e tornou-se símile ao que foi apresentado legalmente no estado de São Paulo, no que se refere ao uso de materiais montessorianos associados ao método froebeliano, nos anos de 1924 e 1925. Outra evidência de seu prestígio no campo educativo é que em novembro de 1923 a mesma assumiu a presidência da Sociedade de Educação de São Paulo. Foi a única mulher na direção desta entidade e teve como secretário Almeida Jr (NERY, 2006).

No entanto, foi o Decreto de 1933 que investiu em tirar a conotação de escola maternal e jardim de infância como distinção entre classes sociais, mesmo que isso já fizesse parte da cultura. Além disto, tal regulamentação torna a chefe do Serviço de Educação Infantil responsável pela propagação dos métodos froebeliano e montessoriano, e também de outros que surjam por meio de pesquisas, mas não faz menção a nenhum outro método de ensino, como havia anunciado Kishimoto (1988). Outrossim, tem também a chefe da Educação Infantil a responsabilidade de incentivar e fiscalizar a disseminação de estabelecimentos públicos e particulares. Apesar de procurar organizar os níveis de ensino, essa declaração deixa evidente que o Estado contava com a iniciativa privada para assegurar a difusão da educação e que a auxiliaria a se proliferar e manter.

\section{CONSIDERAÇÕES FINAIS}

A utilização de novas fontes disponibilizadas pela web, como a Hemeroteca Nacional, associada à narrativa historiográfica possibilitou o uso de novas lentes sobre a história da educação do nosso país e permitiu uma construção historiográfica relacional.

Nesse movimento, houve espaço para a constituição de novas materialidades, como a inauguração da primeira escola montessoriana em São Paulo, por Mary e Ciridião Buarque, para o público infantil de um segmento social específico, num investimento particular que acompanhou a institucionalização da legislação educacional paulista e brasileira, bem como do espaço escolar e da infância enquanto lugar social de necessidades específicas, quando as discussões realizadas pelos intelectuais a respeito dos Jardins de Infância esbarravam na necessidade de disseminação da Escola Primária a fim de alfabetizar a população do país, que em 1920 contava com $72 \%$ de analfabetos (FERRARO et al., 2004).

Entretanto, as apropriações de frações do Método Montessori, principalmente no que se refere ao uso de materiais sensoriais e de móveis compatíveis com o tamanho das crianças, foram adotados por outras instituições particulares ou prescritos pela legislação das Escolas Maternais e Jardins de Infância de São Paulo (1925 a 1933).

Tendo em vista que as orientações oficiais permitem identificar a circulação de ideias, a materialidade, as apropriações relevantes ou os interesses que constituíram as relações político-educacionais em determinado período, no Estado de São Paulo o Método Montessori se ateve à Educação Infantil e foi associado ao uso de materiais concomitantemente à indicação do método froebeliano. Provavelmente essas sejam as primeiras aferições ao uso do material montessoriano de forma desvinculada do método, não o percebendo como um sistema de princípios mais amplo. Nesse viés pretensamente transformador, apresentado por sua apropriação parcial, o Método Montessori foi ressignificado coisificando-se e, nesse afã, recebeu usos variados, numa prática de 
apropriação tecida a partir dos sentidos produzidos, dos reusos, das interpretações instituídas sobre ideias, objetos e impressos em circulação.

Mas, a representação de criança, de infância e de ambiente adequado para a mesma, apropriada por Mary Buarque em seu trabalho com o Método Montessori e em suas vivências como professora, deu origem a uma configuração singular do lugar da criança na mídia radiofônica permitindo que a arte infantil conquistasse um novo olhar e um inaudito espaço social. Com isto, Mary Buarque fez da sua apropriação um vetor que tornou possível a expansão do ethos montessoriano sob outras materialidades.

Ao ser legalmente atrelado ao uso de alguns materiais e às possibilidades de autonomia em sala de aula, não se observando que certas atividades também seriam indícios relevantes da pedagogia montessoriana - tais como a organização da sala para exercícios tranquilos, a atenção destinada aos interesses da criança, a permissão do livre acesso das mesmas aos espaços internos e externos da sala, a relação de aprendizagem estabelecida entre professor e aluno -, constituiu-se uma associação da perspectiva montessoriana às atividades individuais, enquanto as coletivas foram atribuídas a outros expoentes do meio educativo. Essa associação desconsiderou que o Método Montessori também trabalha o coletivo e a colaboração, enquanto investe no desenvolvimento singular do aluno, num modo de viver em que se aprende a moral e as regras sociais ao delas se fazer uso.

Artigo recebido em: 19/12/2017

Aprovado para publicação em: 11/03/2018

\section{THE AMERICAN TREND OF MONTESSORI METHOD IN SÃO PAULO: CIRIDIÃO BUARQUE AND MARY BUARQUE}

ABSTRACT: Montessori founded a public school for children at risk in 1907 in Rome, the Casa dei Bambini, which was spread transnationally and created innovative educational practices and thinking. The object of this historiographical narrative was to study the institutionalization of the Montessori Method in Brazil, problematizing its form of appropriation and identifying why the method is mainly related to the use of specific didactic materials and furniture appropriate to the size of children. It was verified that the first Montessor school in Brazil attended the children's public, at São Paulo, in the year 1915, in a private investment of Ciridião Buarque and Mary Buarque. This pedagogy was irradiated through the appropriations made by the teachers of the Escola Normal da Praça, and the legislation that indicated the use of Montessori and Froebel didactic materials, but in a disjointed form of such pedagogical principles. Evidence of the use of the Montessori Method in a non-restricted perspective on the use of didactic material was found in children's radio programs.

KEYWORDS: History of Education. Child Education. Montessori method. Brazilian educational institutions.

\section{LA TENDENCIA AMERICANA DEL MÉTODO MONTESORI EN SÃO PAULO: CIRIDIÃO BUARQUE Y MARY BUARQUE}


RESUMEN: Montessori constituyó, en 1907, en Roma, una escuela pública para niños en situación de riesgo, la Casa dei Bambini, que difundida transnacionalmente configuró prácticas y pensamiento educativo innovadores. El objeto de esta narrativa historiográfica fue estudiar la institucionalización del Método Montessori en Brasil, problematizando su forma de apropiación e identificando por qué el método está relacionado principalmente al uso de materiales didácticos específicos y de mobiliario adecuado al tamaño de los niños. Se constató que la primera escuela montessoriana en Brasil atendió al público infantil, en São Paulo, en el año de 1915, en una inversión particular de Ciridião Buarque y Mary Buarque. Esta pedagogía se irradió por intermedio de las apropiaciones realizadas por los docentes de la Escola Normal da Praça, y de la legislación que indicaba el uso de materiales didácticos de Montessori y de Froebel, pero de forma desarticulada de tales principios pedagógicos. Evidencias de la utilización del Método Montessori en perspectiva no restringida al uso de materiales didácticos se encontraron en los programas infantiles radiofónicos.

PALABRAS CLAVE: Historia de la educación. Educación del niño. Método Montessori. Instituciones educativas brasileñas.

\section{NOTAS}

1) A Educação era uma "revista que procurava ser popular, de baixo custo, assentada em corpo de jornalistas e literatos, contando como colaboradores Francisco Rangel Pestana, Francisca Júlia, entre outros" (MARTINS, 2008, p.304). De acordo com a mesma autora (Ibidem), "a ênfase da República no projeto educacional, conforme proclamava o discurso liberal da época, encontrou algum rebatimento no periodicismo pedagógico, conhecendo-se títulos de peso, em especial [...] Revista do Ensino (1902), Educação (1902), Revista dos Educadores (1912)". Mas, algumas tiveram curta duração, estendendo-se até 1918 e refletem "a relatividade do amparo à instrução tão amplamente divulgado pelo Estado republicado" (Ibidem). Naquele momento, "[...] a iniciativa oficial voltou-se, isso sim, para empreendimento escolar que privilegiou a construção de uma rede física de estabelecimentos, edificações qualificadas na arquitetura do período, senão de caráter suntuoso, senão de grande visibilidade para um projeto que na prática não ocorreu; ou por outra, manteve o mesmo status quo, de acesso escolar à parcela privilegiada da população" (Ibidem).

2) A Universidade de Colúmbia, em Nova York, possuía vínculo com a Escola Americana e com o Mackenzie College, em São Paulo.

3) CORREIO PAULISTANO. Terceiro Congresso Panamericano da Criança, 2 set 1922; Conferência da Criança. 30ago1922; Curso de Violão, 2set1934; Vesperaes cinematographicas infantis, 31 jan 1935; Caravana das professoras que vão a Buenos Aires acompanhadas de Lourenço Filho, 3 abr1935; Espetáculo de gente pequena para gente grande, 23 abr 1935.

4) Conseguimos afirmar apenas que Lúcia Pacheco Jordão era membro do Instituto de Educação da capital paulistana e que provinha de uma tradicional família de Itu. De acordo com Kishimoto (1988, p.154), Lúcia e sua irmã Helena Pacheco Jordão eram proprietárias do Externato Pacheco Jordão, situado à R. Consolação, n.38, em São Paulo. Sobre Pedro Deodato de Moraes, entretanto, há uma explanação mais minuciosa ainda neste capítulo.

5) Jornal Correio Paulistano. Terceiro Congresso Americano da Criança. 2 de setembro de 1922.

6) A Rádio Kosmos, a rádio com sotaque paulista, foi inaugurada em 1934, quando a radiofonia brasileira estava em plena expansão, sobretudo no estado de São Paulo, onde foram criadas em 
1923 a Rádio Educadora Paulista (que se tornou a Gazeta em 1943), a Record em 1929, a DKi (Cultura) em 1933, a América em 1934 ou a Tupi em 1937. (ADAMI, 2008).

7) "Essa dualidade da educação pré-escolar enquadra-se em um sistema educativo que discrimina outros níveis de ensino. É bastante conhecida a dualidade do ensino secundário, com a determinação dos ginásios secundários para a elite intelectual, com acesso ao ensino superior e os ginásios profissionalizantes para o povo impedindo-o de dirigir-se ao curso superior. Essa duplicidade de sistemas educacionais manifesta-se também no ensino superior, com a aceitação da Politécnica, Direito e Medicina como escolas de altos estudos, vedando-se à Escola Agrícola Luiz de Queiroz o direito de ser instituto superior de altos estudos." (KISHIMOTO, 1988, p. 41).

8) Antônio de Almeida Jr. foi professor, médico e, posteriormente, político. Destaco a sua relação próxima com o ensino na Escola da Praça, como pertencente ao grupo que assinou o Manifesto dos Pioneiros de 1932 e como um dos fundadores da Universidade de São Paulo.

\section{REFERÊNCIAS}

ADAMI, Antônio. O rádio com sotaque paulista: Rádio Cosmos e Rádio América. In: CONGRESSO BRASILEIRO DE CIÊNCIAS DA COMUNICAÇÃO, 31. INTERCOM. NATAL, 2008, Natal. Anais do Congresso Brasileiro de Ciências da Comunicação. Natal, 2008. p.1-10. Disponível em:<http://www.intercom.org.br/papers/nacionais/2008/resumos/R3-22091.pdf >. Acesso em: 08 fev. 2016.

CORREIO PAULISTANO. A educação da infância normal e das crianças mentalmente atrasadas, na América Latina. Basílio de Magalhães. Correio Paulistano, São Paulo, 19 de fevereiro de 1917. Disponível em:

<http://memoria.bn.br/DocReader/DocReader.aspx?bib=090972_06\&pesq=montessori \&pasta $=$ ano\%20191 >. Acesso em: 23 fev. 2015.

CORREIO PAULISTANO. A educação esthetica na infância. Correio Paulistano, São Paulo, 4 de dezembro de 1927d. p. 3. Disponível em:

<http://memoria.bn.br/DocReader/Hotpage/HotpageBN.aspx?bib=090972_07\&pagfis= 28050\&pesq=\&url=http://memoria.bn.br/docreader\#>. Acesso em: 15 nov. 2014.

CORREIO PAULISTANO. Caravana das professoras que vão a Buenos Aires acompanhadas de Lourenço Filho. Correio Paulistano, São Paulo, 23 de abril de 1935b. p. 2. Disponível em:

$<$ http://memoria.bn.br/DocReader/Hotpage/HotpageBN.aspx?bib=090972_08\&pagfis= 14684\&pesq=\&url=http://memoria.bn.br/docreader\#>. Acesso em: 26 jun. 2016.

CORREIO PAULISTANO. Conferência da Criança. Correio Paulistano, São Paulo, 30 de agosto de 1922b. Disponível em:

<http://memoria.bn.br/DocReader/Hotpage/HotpageBN.aspx?bib=090972_07\&pagfis= 38089\&pesq=\&url=http://memoria.bn.br/docreader\#>. Acesso em: 12 set. 2014. 
CAMPOS, S. B.

CORREIO PAULISTANO. Curso de Violão. Correio Paulistano, São Paulo, 2 de setembro de 1934. p. 4. Disponível em:

<http://memoria.bn.br/DocReader/Hotpage/HotpageBN.aspx?bib=090972_08\&pagfis= 14684\&pesq=\&url=http://memoria.bn.br/do>. Acesso em: 26 jun. 2016.

CORREIO PAULISTANO. Defesa nacional: Sgto Castello Branco contrapõe-se aos métodos da Escola Nova. Correio Paulistano, São Paulo, 27 de janeiro de 1928. p. 4. Disponível em: <http://memoria.bn.br/DocReader/Hotpage/HotpageBN.aspx?bib=090972_07\&pagfis= 28050\&pesq=\&url=http://memoria.bn.br/docreader\#>. Acesso em: 15 nov. 2014.

CORREIO PAULISTANO. Escola Montessori. Correio Paulistano, São Paulo, 31 de março de 1927b. Disponível em:

<http://memoria.bn.br/DocReader/Hotpage/HotpageBN.aspx?bib=090972_07\&pagfis= 38089\&pesq=\&url=http://memoria.bn.br/docreader\#>. Acesso em: 12 set. 2014.

CORREIO PAULISTANO. Espetáculo de gente pequena para gente grande. Correio Paulistano, São Paulo, 23 de abril de 1935c. p. 6. Disponível em:

<http://memoria.bn.br/DocReader/Hotpage/HotpageBN.aspx?bib=090972_08\&pagfis= 14684\&pesq=\&url=http://memoria.bn.br/docreader\#>. Acesso em: 26 jun. 2016.

CORREIO PAULISTANO. Mensagem apresentada na Assembleia Legislativa do Amazonas. Correio Paulistano, São Paulo, 26 de agosto de 1927a. p. 7. Disponível em:

$<$ http://memoria.bn.br/DocReader/DocReader.aspx?bib=090972_07\&PagFis=27219\&Pe sq=cegos $>$. Acesso em: 26 mar. 2016.

CORREIO PAULISTANO. Mensagem apresentada na Assembleia Legislativa do Amazonas. Correio Paulistano, São Paulo, 26 de agosto de 1927c.

CORREIO PAULISTANO. Primeiro Congresso de Educação Nacional. Correio Paulistano, São Paulo, 28 de dezembro de 1927b. p. 4. Disponível em:

<http://memoria.bn.br/DocReader/Hotpage/HotpageBN.aspx?bib=090972_07\&pagfis= 28050\&pesq=\&url=http://memoria.bn.br/docreader\#>. Acesso em: 12 jan. 2016.

CORREIO PAULISTANO. Reforma de instrução pública em São Paulo. Correio Paulistano, São Paulo, 24 de junho de 1925. p. 4. Disponível em:

<http://memoria.bn.br/DocReader/Hotpage/HotpageBN.aspx?bib=090972_07\&pagfis= 28050\&pesq=\&url=http://memoria.bn.br/docreader\#>. Acesso em: 15 nov. 2014.

CORREIO PAULISTANO. Sampaio Dória, diretor de instrução pública. Correio Paulistano, São Paulo, 13 de maio de 1920. p. 3. Disponível em:

<http://memoria.bn.br/DocReader/Hotpage/HotpageBN.aspx?bib=090972_07\&pagfis= 28050\&pesq=\&url=http://memoria.bn.br/docreader\#>. Acesso em: 15 nov. 2014.

CORREIO PAULISTANO. Terceiro Congresso Panamericano da Criança. Correio

Paulistano, São Paulo, 2 de setembro de 1922a. Disponível em: 
$<$ http://memoria.bn.br/DocReader/Hotpage/HotpageBN.aspx?bib=090972_07\&pagfis= 38089\&pesq=\&url=http://memoria.bn.br/docreader\#>. Acesso em: 12 set. 2014.

CORREIO PAULISTANO. Vesperaes cinematographicas infantis. Correio Paulistano, São Paulo, 31 de janeiro de 1935a. p. 8. Disponível em:

$<\mathrm{http} / /$ memoria.bn.br/DocReader/Hotpage/HotpageBN.aspx?bib=090972_08\&pagfis= 14684\&pesq=\&url=http://memoria.bn.br/docreader\#>. Acesso em: 26jun. 2016.

HOLANDA, B. B. de. Buarque: uma família brasileira. Ensaio histórico-genealógico. Rio de Janeiro: Casa da Palavra, 2007. Disponível em:

$<$ https://books.google.com.br/books?id=RDU9RL5kQ7UC\&pg=PA16\&lpg=PA16\&dq=livr o+buarque+uma+familia+brasileira\&source=bl\&ots=oofe-

Dzduu\&sig=p27hSf1GKTQiuaxQMVTOtct10JQ\&hl=pt-

BR\&sa=X\&ei=0M_PVMOFCZHbsATYqoL4DA\&ved=0CEwQ6AEwBA\#v=onepage\&q=livro \%20buarque\%20uma\%20familia\%20brasileira\&f=false >. Acesso em: 20 dez. 2014.

INSTITUTO DE EDUCAÇÃO CAETANO DE CAMPOS (IECC). Manoel Ciridião Buarque, Intercâmbio de alunos para os Estados Unidos e introdutor da Língua Portuguesa na Universidade de Colúmbia. Polianteia Comemorativa dos Cem anos da Escola Normal,1846-1946, p. 93. Caetano de Campos. A escola que mudou o Brasil, 2015. Disponível em: $<$ http://www.iecc.com.br/diretores-e-professoresbiografias/261/manuel-ciridiao-buarque-intercambio-de-alunos-para-os-estadosunidos-em-1915-e-introdutor-da-lingua-portuguesa-na-universidade-de-columbia $>$. Acesso em: 25 jan. 2015.

KISHIMOTO, T. M. A pré-escola em São Paulo (1877 a 1940). São Paulo: Edições Loyola, 1988.

MARTINS, A. L. Revistas em revistas. imprensa e práticas pedagógicas em tempos de República. São Paulo (1890-1922). São Paulo: Editora da USP, 2008. Disponível em: $<$ https://books.google.com.br/books?id=ykMxfxllH0sC\&pg=PA304\&lpg=PA304\&dq=mo Idando+gera\%C3\%A7\%C3\%B5es+revista+pedag\%C3\%B3gica+ana+luiza+martins\&sour $\mathrm{ce}=$ bl\&ots=Kc1VPyTSgA\&sig=wODF4O_PZ1Kbf6STM_SxyjV4fSE\&hl=pt-

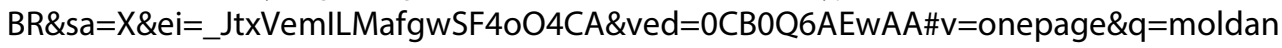
do\%20gera\%C3\%A7\%C3\%B5es\%20revista\%20pedag\%C3\%B3gica\%20ana\%20luiza\%20 martins\&f=false $>$. Acesso em: 03 fev. 2015.

MAGALHÃES, J. Tecendo nexos. histórias das instituições educativas. Bragança Paulista: EDUSF, 2004.

SÃO PAULO. Decreto no 3.708, de 30 de abril de 1924:aprova o Regimento Interno das Escolas Maternaes. Disponível em:<http://www.al.sp.gov.br/repositorio/legislacao/decreto/1924/decreto-370830.04.1924.html $>$. Acesso em: 15 jan. 2016. 
CAMPOS, S. B.

SÃO PAULO. Decreto no 3.847, de 14 de maio de 1925: Aprova o Regulamento das Escolas Maternais. Disponível em:

<http://www.al.sp.gov.br/repositorio/legislacao/decreto/1925/decreto-3847-

14.05.1925.html>. Acesso em: 15 jan. 2016.

SÃO PAULO. Decreto no 5.884, de 21 de abril de 1933: Institui o Código de Educação do Estado de São Paulo. Disponível em:<http://www.al.sp.gov.br/repositorio/legislacao/decreto/1933/decreto-588421.04.1933.html >. Acesso em 15 jan. 2016.

Simone Ballmann de Campos: Possui graduação em Pedagogia pela Universidade Federal de Santa Catarina (1993), especialização em Psicopedagogia pela Universidade do Sul de Santa Catarina (2001), mestrado em Educação pela Universidade do Estado de Santa Catarina (2006) e doutorado em educação pela UNiversidade Federal de Santa Catarina (2017). Atualmente é coordenadora pedagógica no Centro Educacional Menino Jesus (CEMJ), professora na Universidade de São José (USJ) e participante do Grupo de Pesquisa Grupo GEPHIESC.

E-mail: siballmann@yahoo.com.br 